\title{
ASSESSMENT OF SHEAR STRENGTH PARAMETERS OF SOIL FROM LOAD MICROPILE TESTS
}

\author{
KAREL VoJTASÍK \\ V̆̌B - Technical Univerisity of Ostrava, Faculty of Civil Engineering, Deparment of Geotechnics and \\ Underground Engineering, Ludvíka Podéště 1875/17, 70833 Ostrava-Poruba, Czech Republic \\ correspondence: karel.vojtasik@vsb.cz
}

\begin{abstract}
Design and evaluation of the bearing capacity of micropiles are based on shear strength parameters of the soil within which a micropile is installed. These parameters are mostly received from laboratory tests or as an expert evaluation relying on soil description, classification and collected experience. This paper presents an approach that determines cohesion and angle of internal friction from diagrams of displacement on load, these being obtained by compression and traction load tests of real micropiles installed in the known soil. Furthermore, the diagrams are interpreted by the Mohr-Coulomb strength criterion and the desired values of shear strength are thus derived by using it.
\end{abstract}

KEYworDs: Displacement on load diagram, load test, micropile, Mohr-Coulomb, shear strength, soil.

\section{INTRODUCTION}

Bearing capacity of the micropile is determined by the state and shear strength parameters of the ground within which a micropile is installed. The bearing capacity of the micropile is evaluated in terms of limit stability states regarding either peak or residual stability. The achievement of the respective state is conditioned by the displacements of micropile in the ground.

Calculations of the bearing capacity most often rely on data obtained either on samples tested in the laboratory or on an expert estimate by classification. Both these input data do not take into account state conditions completely and indeed has never given technological procedures for micropile installation, yet both of which also contribute significantly to the bearing capacity.

A more reliable picture of the micropile bearing capacity is offered by a load test on site, which will give a respective diagram of the displacement on load. Unlike computational methods based on laboratory or expert data, this approach encompasses the state conditions and technological procedures of micropile installation.

This diagram of the displacement on load comprises also the peak and residual limit stability states. The respective load forces extracted from the diagram may be utilised for further back analysis to evaluate the shear strength parameters of soil.

The article here presented sets out a method employing a force calculation formula of micropile bearing capacity and an interpretation of the diagram following the Mohr-Coulomb criterion of shear strength.

\section{Introductory COMMENT ON METHOD}

There is a fundamental assumption that the shear strength development in soil ground should be generally the same regardless of whether it is a laboratory test (Figure 1) or a practical field situation, such as in the case of a micropile bearing capacity.

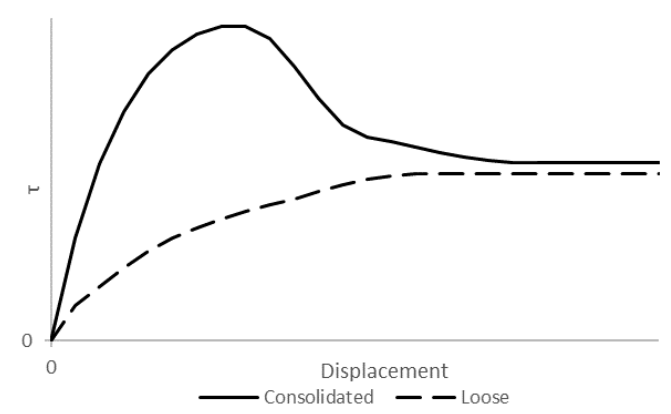

FiguRE 1. Diagram of box shear tests.

Determination of strength parameters is based on results of two types of tests performed in a certain order on the same micropile. The compression test is performed first, followed by the traction test. This order of testing ensures that during the compression test both strength parameters are actively combined and at the end of this test procedure the cohesion of soil ground is derived completely. In the traction test that follows immediately there can be mobilised only the angle of internal friction because, after the previous pressure test, the cohesion on the shear surface became zero.

The output of both kinds of test are the diagrams of displacement on load (Figure 2) that have an analogous course with the shear strength on the displacement course of the soil sample obtained by standard 
box shear tests.

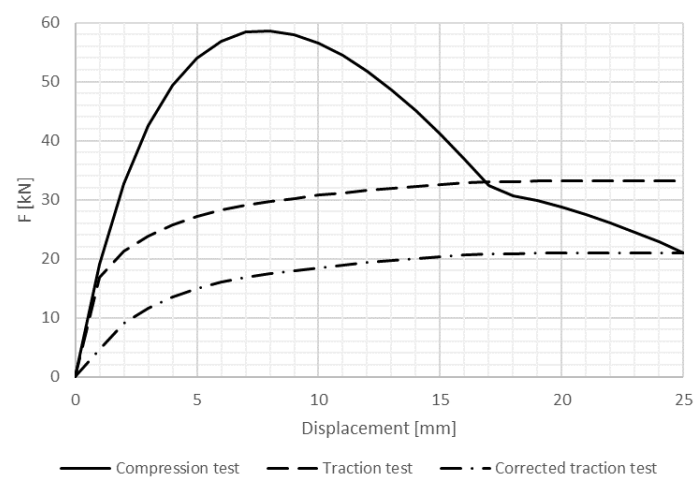

Figure 2. Graphs of the course of loading tests of a micropile.

A second assumption is that the peak limit state contains both soil shear strength parameters and the residual limit state contains only one, namely the angle of internal friction. The peak limit state corresponds to the load of the peak force $F_{p}$ that represents the maximal recorded value during the test. The residual limit state corresponds to the load of the force $F_{r}$ that occurs at a displacement of $25 \mathrm{~mm}$ of micropile.

A third assumption consists in analysing the peak force $F_{p}$ and the residual force $F_{r}$ by the shear strength Morh-Coulomb criterion $\tau=c+\sigma \tan \phi$. The peak force $F_{p}$ extracted from diagram of displacement on load by compression test there is derived a peak shear resistance $T_{p}$ at the tube shape surface of the micropile and this equals the sum of a shear resistance due to cohesion $T_{c}$ and a shear resistance due to angle of internal friction $T_{\phi}$.

$$
T_{p}=T_{c}+T_{\phi}
$$

The peak shear resistance is given by the peak force according to the formula:

$$
T_{p}=\frac{F_{p}}{\pi d l}
$$

where:

d diameter of tube shape surface of mircopile

1 length of tube shape surface of micropile (length of micropile)

The shear resistance due to the angle of friction is present in both kinds of test during the whole course of tests so the shear resistance due to angle of internal friction is gained by the residual force according to the formula:

$$
T_{\phi}=\frac{F_{r}}{\pi d l}
$$

The resistance due to cohesion only is the difference between the peak shear resistance and the shear resistance due to angle of internal friction. The value of this difference is the cohesion.

$$
T_{c}=T_{p}-T_{\phi}=c
$$

The residual force $F_{r}$ cannot be applied for evaluation of the angle of internal friction $\phi$ because the shear resistance due to the angle of friction involves also normal stress $\sigma$ at the outer surface of the micropile body $\left(T_{\phi}=\sigma \tan \phi\right)$. The normal stress is hard to verify experimentally on site by measurement. Also, a common exact determination encounters a problematic coefficient of lateral pressure, for which there is no point in determining in the usual way, because the soil has been grouted with high grouting pressure and the grouting medium has undergone a phase transformation from a liquid to a solid one. Thus, the possible way to determine the normal stress and also the unknown angle of internal friction in question offers a variation in approach with variation parameters $\sigma$ and $\phi$. The key parameter in the variation calculations is the peak force $F_{p}$ as it includes the both cohesion and angle of internal friction. The peak force is put into a modified formula 1 The remaining parameters are either derivable as $T_{c}$ or measured $F_{p}$.

$$
\frac{F_{p}}{\pi d l}=\sigma \tan \phi
$$

The variation approach provides many combinations of values $\sigma$ and $\phi$ satisfying the formula 5 Finally there are selected those ones fitting the relevant values expected at the respective ground site.

\section{Description of Tests}

The displacement on load diagrams were processed with data obtained experimentally from two series of tests. A group of four micropiles was first subjected to a compression load force and after this the micropiles were loaded again, this time with a traction load force. The micropiles were installed on the site of the external testing frame at VŠB TUO, FAST.

\subsection{Micropile}

The tests were conducted on a micropile from a steel hollow rod of a spindle shape casing, type R32. The length of each of the four micropiles was 3 meters. Each micropile ended with a drill bit of diameter $45 \mathrm{~mm}$. The micropile was installed by percussion drilling and after subsequently grouted from the micropile tip with a synthetic epoxy resin. The grouting pressure was about of 8-10 MPa and delivery of the resin was terminated when it ascended to surface (Figure 3). This design is widely implemented in practice to enhance the bearing capacity of a foundation. 


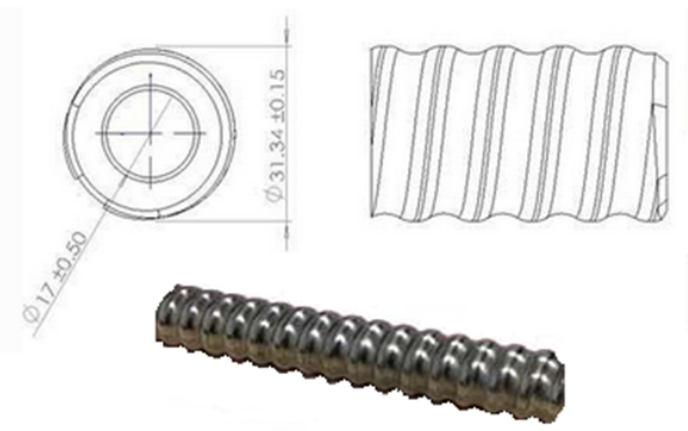

Figure 3. Micropile from steel hollow rod of a spindle shape casing (type R32).

Atop of the micropile steel rod is incorporated a concrete prismatic cube. The concrete prismatic cube is necessary to facilitate the installation of a hydraulic press on the lender micropile body and to secure a coaxial transfer of compression load force in the micropile. The smallest deviation in coaxial transfer causes a bending of a slender micropile body and it consequently leads to serious distortion in the values of micropile axial displacement. The concrete prismatic cube has dimensions $40 \times 40 \times 50 \mathrm{~cm}(50 \mathrm{~cm}$ is the height of the cap). In the concrete prismatic there is embedded a short section micropile equipped with steel plate and a nut to fix the plate (Figure 4).

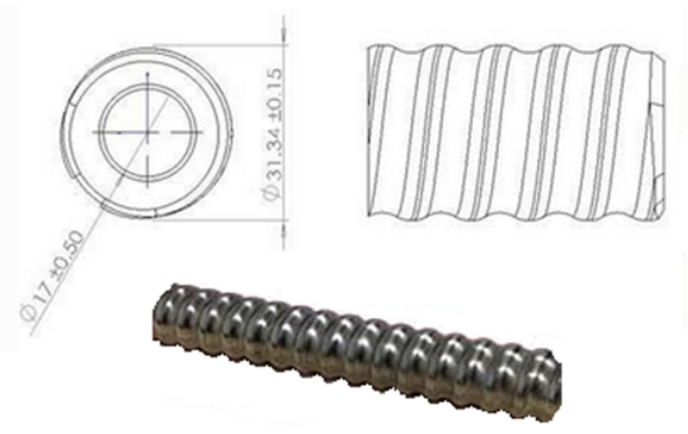

Figure 4. Concrete prismatic cube.

In the traction load force test a traction load force is applied directly on the end of the micropile. The micropiles are installed inside an outdoor steel test frame. The micropiles are positioned in a square layout and the spacing of the micropiles axes is $1.2 \mathrm{~m}$. The distance of the micropiles to the steel test frame foundations is $1.34 \mathrm{~m}$.

\subsection{GROUND}

All micropiles are installed in a ground profile that consists of an artificial layer of compacted clayey sand of thickness approx. $0.8 \mathrm{~m}$, which replaces the original top layer consisting of anthropogenic sediments and soil with a high organic content (topsoil and sub-soil). The concrete prismatic cube is placed in it. Then there follows a monotonous layer of loess to a depth of approx. $5.5 \mathrm{~m}$ and glacial sand and gravel are below this. The parameters of the loess are summarised in Table 1 .

\subsection{Compression LoAd Test}

The compression load test is carried out on the micropile together with the concrete prismatic cube on the micropile head. A compression load is generated by a hydraulic press, which is propped against the horizontal beam of the steel test frame through a steel support extension. The hydraulic press is placed on a steel plate with dimensions of $0.4 \times 0.4 \times 0.03 \mathrm{~m}$. Its role is to avert possible crushing of the top of a concrete prismatic cube and eliminate deformation when a higher load force sets in. It provides a base for four potentiometer transducers placed at plate corners to measure micropile settlement. The force is read out by a hydraulic press pressure sensor. The installation of the hydraulic press on the micropile is shown in Figure 5

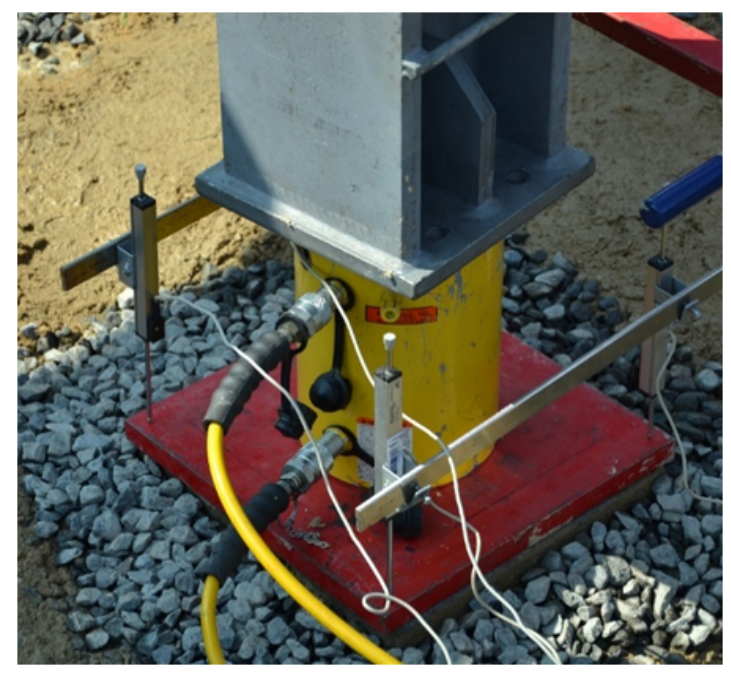

Figure 5. Installation of hydraulic press on the micropile at the micropile compression load test.

All four micropiles were tested with the same regime of applying compression forces. The compression forces were increased in steps and after each step there followed a time break which was necessary to accomplish the full settlement of the micropile in each respective force step. The value of a force in the step was the same in all the steps and it was $10 \mathrm{kN}$. The break time was 5 minutes and it proved to be sufficient to complete the full micropile settlement in the respective force step. The compression test took place until the value of the $25 \mathrm{~mm}$ settlement of the micropile was exceeded.

Additionally, a concrete prismatic cube without a micropile, placed close to the micropiles in the same soil ground, was tested in a compression test. It was tested with the same instrumentation and load regime and during the test a respective diagram displacement on load was recorded.

The diagram displacement on load of only the micropile without the concrete prismatic cube is derived as the difference of displacements of the micropile together with the concrete prismatic cube and a concrete prismatic cube. Figure 6 shows the diagrams 


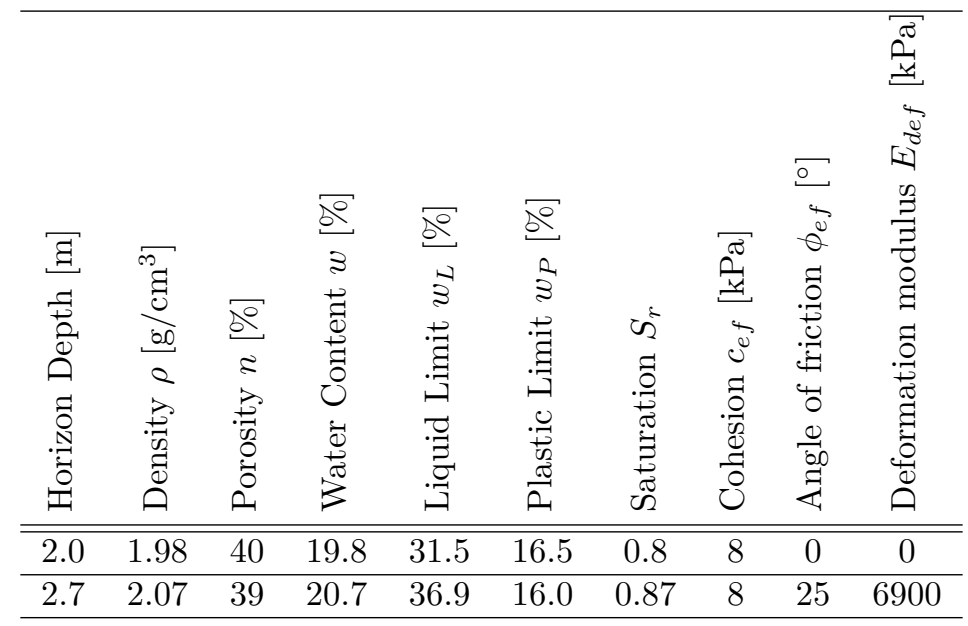

TABLE 1. The parameters of ground

of displacement on load measured on the micropile together with the concrete prismatic cube $\left(F_{m+h}\right)$, on the sole concrete prismatic cube $F_{h}$ and the derived diagram for micropile only $F_{m}$.

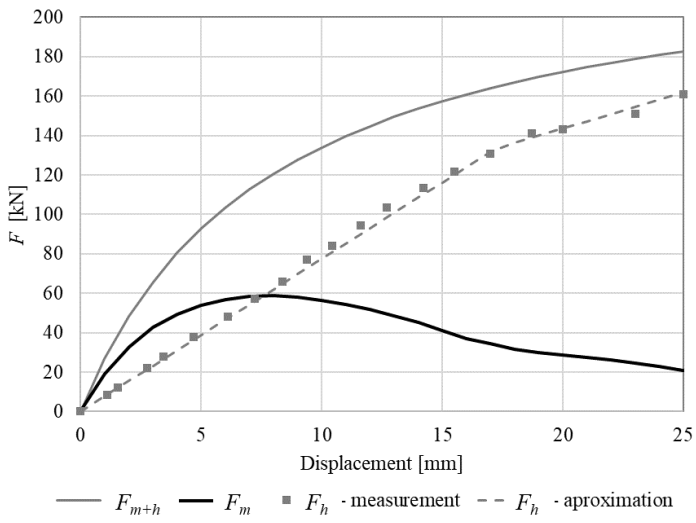

FiguRE 6. Diagrams of the compressions tests.

\subsection{Traction Load Test}

The traction load test is carried out on the same micropiles shortly after the compressive load. The concrete prismatic cube is taken away and a traction rig installed above the micropile on ground around the micropile. The traction rig consists of a steel trestle specially constructed for this purpose. The trestle bears a hydraulic press and on its piston there is attached a traction mechanism assembled from two thick steel square plates and four steel rods that join both plates holding stiff together. One plate rests on a press piston the second is fixed with a screw to the micropile. The assembly of the traction rig and its installation on the micropile is shown in Figure 7.

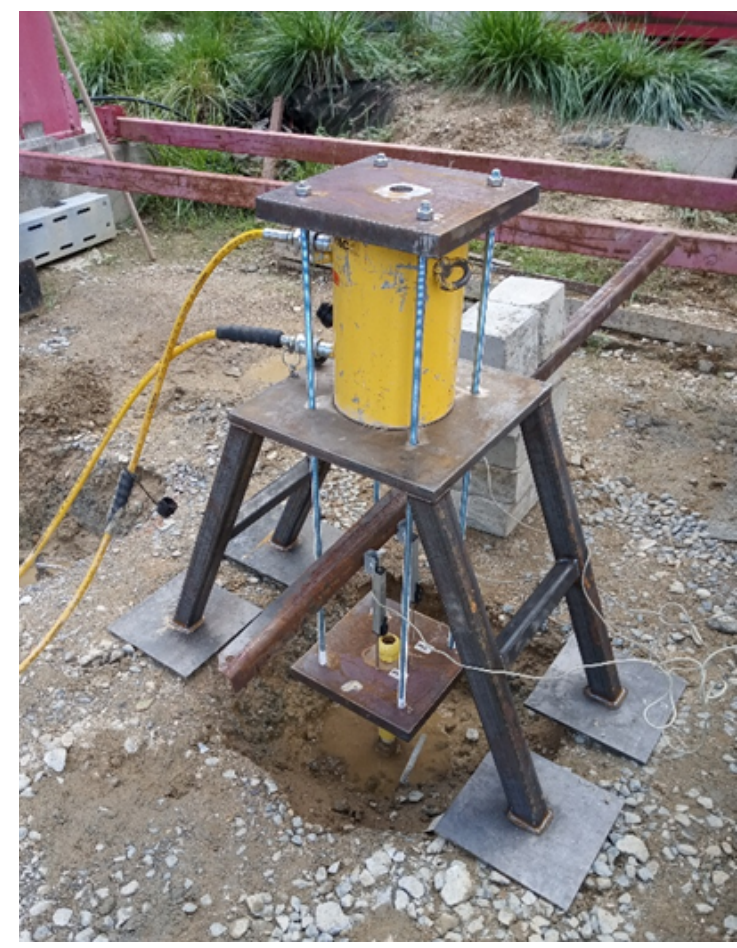

FiguRE 7. Installation of the traction rig at micropile traction load test.

The regime of applying traction forces was identical with the compression load test. The only difference between both kinds of tests is that traction displacement of the micropile is measured just with two potentiometer transducers. Both transducers are placed on a lower steel plate close to the micropile top in a straight line going approximately through a micropile axe.

After traction tests all four micropiles were pulled out from the ground at the end of the traction test. The diameters of the micropile column body along the whole length vary in the range between 70 to $80 \mathrm{~mm}$. The steel rods are coated completely with grouted soil , from the bottom of the concrete prismatic cube to the drill bit. (Figure 8). 


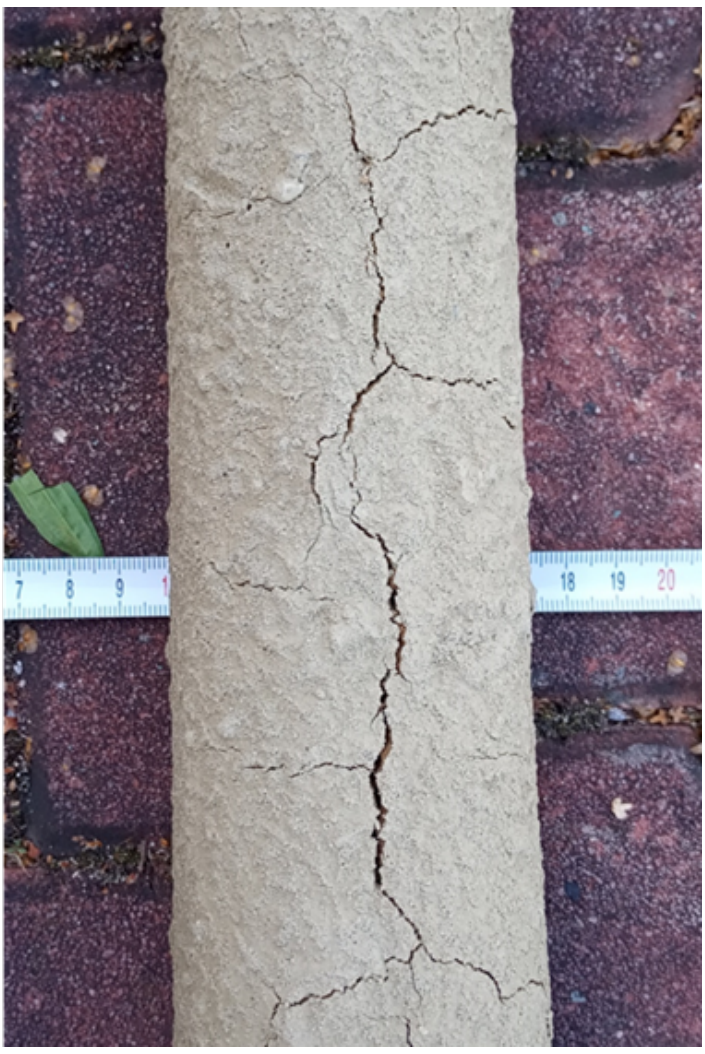

Figure 8. The state of the tube shape surface of the micropile after being pulled out of the ground.

\section{Results}

The input data assigned straight from the diagram of tests (Figure 2) are the load force of the peak bearing capacity $F_{p}$ taken from the diagram of the compression load test. It amounts to $59 \mathrm{kN}$. Another is the load force at the residual bearing capacity $F_{r}$. It is read as a displacement of micropile of $25 \mathrm{~mm}$. In the case of a compression load test it amounts to $21 \mathrm{kN}$, while in the case of a traction load test it is greater and amounts to $32 \mathrm{kN}$. The last straightly assigned parameter is the diameter of a tube shape of micropile determined by measurement after the extraction micropiles out of the ground. This amounts to about $0.075 \mathrm{~m}$ (Figure 8). The last parameter is the length of the micropile which is $3 \mathrm{~m}$.

Before performing the calculations according to the relationships ??, it is necessary to explain the different course of the diagrams from both tests and further justify why there was no agreement between the courses and values of residual force in the residual strength stage, as would be expected.

The diagram of the traction test does not display any peak in load force in contrast with the diagram for the compression test because during this test cohesion of soil ground should be zero, while it has been drawn out in the preceding compression test. The peak force at the compression test is due to cohesion at the tube shape surface of the micropile and resistance as the ground acts against the micropile base tip. The base is not large and therefore its contribution is disregarded in the analysis.

The apparent difference in residual load forces at both tests is probably due to the different development of pore pressure on the tube shape surface of the micropile. In the pressure test the pore pressure will be positive, while in the tensile test it will be negative due to a suction. Unfortunately, the pore pressure on the tube shape surface of the micropile is almost impossible to determine by measurement on site.

The suction influences and raises the value of the measured residual force in a traction test. This is a reason why the measured value forces at the traction test must be corrected for the suction effect. The suction acts as cohesion on the tube shape surface of the micropile along with friction. The correction force due to suction $F_{s}$ is chosen intentionally as the difference between the residual forces of both tests for the $25 \mathrm{~mm}$ displacement and this is about $12 \mathrm{kN}$. The measured forces in the traction test are all reduced exactly by this value.

The cohesion is calculated according to the modified formula 4 complemented with the effect of suction

$$
c=\frac{F_{p}-\left(F_{r t}-F_{s}\right)}{\pi d l}
$$

where

$F_{r t}$ is the residual force of traction test

The cohesion is calculated from the values read from the graph of forces at a displacement of $8 \mathrm{~mm}$ at which the loading force in the pressure test reached a maximum.

$$
c=\frac{59-(33-12)}{\pi \times 0.075 \times 3.0}=58 \mathrm{kPa}
$$

The variation calculations formula is

$$
\frac{59}{\pi \times 0.075 \times 3.0}-58=\sigma \tan \phi
$$

The result of variational calculations that satisfy the condition given by formula 8 is presented by the graph in Figure 9. The relevant combinations of discovered parameters can be read from the graph.

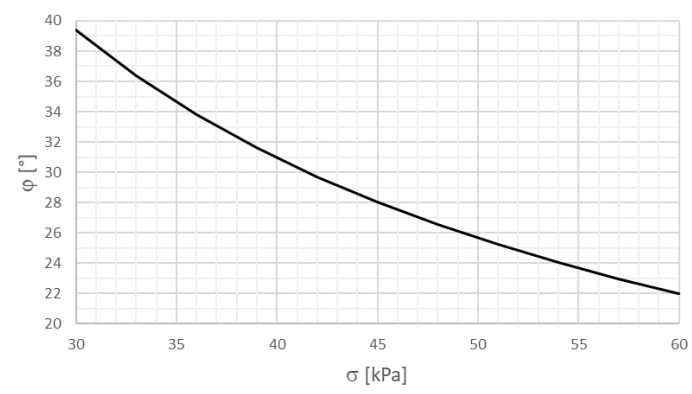

Figure 9. The graph of combinations of values $\sigma$ and $\phi$ satisfying formula 8

The determination of an angle of internal friction depends on the choice of a magnitude of the normal stress on the tube shape surface of the micropile. 
In the case of a standard situation this magnitude changes with depth and should be same as the horizontal earth stress at rest.

The micropile is grouted with a grouting pressure of 8-10 MPa, which is several times higher than a horizontal compound of earth stress value at geostatic stress state in the ground. Further, the type of ground has $40 \%$ porosity and a degree of saturation between 80 and $90 \%$. Thus, there might be expected a normal stress definitely greater than horizontal earth stress at rest. Keeping these facts in mind the normal stress might achieve a state where the horizontal compound of stress might be the same as the vertical compound of stress. An effect of grouting might be that the horizontal compound of stress does not depend on the depth and might have approximately constant magnitude along the micropile.

The values on the axis $\sigma$ range from 30 to $60 \mathrm{kPa}$, and these are consistent with the vertical compound of stress at a depth in the middle of the micropile and respectively at the micropile tip.

A photograph on the Figure 8 , displaying the micropile after being pulled out of the ground and that was used to determine the diameter of it, can be also helpful. The tube shape surface of the micropile is visibly not smooth but rough. The roughness of the tube shape surface of the micropile can contribute to a decision about the magnitude of angle of internal friction indirectly.

For the normal stress of $45 \mathrm{kPa}$, which is a middle point within the range 30 and $60 \mathrm{kPa}$, the respective angle of internal friction is $28^{\circ}$. This is slightly greater by about $3^{\circ}$ than the value of $25^{\circ}$ established at the laboratory which complies with a normal stress of 50 $\mathrm{kPa}$.

\section{Discussion}

The derivation of the diagram of displacement on load for compression load of the micropile is based on an assumption that the total work performed by the micropile together with the concrete prismatic cube $W_{t}$ must be the sum of the work of the concrete prismatic head $W_{h}$ and the micropile without concrete prismatic cube $W_{m}$.

$$
W_{t}=W_{h}+W_{m}=F_{m+h} s=F_{h} s+F_{m} s
$$

where:

\section{$s$ displacement}

$F_{m+h}$ compression force at the micropile together with the concrete prismatic cube

$F_{h}$ compression force at concrete prismatic cube only

$F_{m}$ derived compression force at micropile only without concrete prismatic cube

$$
F_{m}=F_{m+h}-F_{h}
$$

The laboratory data (Table 1) do not correspond exactly to the results derived by the presented method. There is an obvious big difference in cohesion. The value of cohesion received from the laboratory test of $8 \mathrm{kPa}$ corresponds with soft consistency and the value seems to be low with regard to a stiff consistency state of soil ground on the testing site. The laboratory value is likely devalued by sampling, transport, and handling of the ground sample before testing. Another reason for the different values may be that the force boundary conditions in the laboratory test did not correspond to those on the site. The cohesion value of $58 \mathrm{kPa}$ derived from the compression test is significantly greater than the laboratory value but not outside the range of the stiff soil ground consistency. In the value of the angle of internal friction there is a satisfactory agreement with the range of possible values of normal stresses and also the value determined in the laboratory.

\section{Conclusion}

The paper gives us knowledge that the search for, and finding a solution to, a specific geotechnical situation lies in the suitable application of general basic principles. In our case, the derivation of the shear strength parameters of soil ground was based on analysis of diagrams of displacement on load of micropiles. The parameters were derived from comparison with appropriate diagrams between shear strength and displacement of consolidated and soft soil that result from box shear tests and interpretation of the respective diagrams by the Mohr-Coulomb strength criterion.

The results of shear strength determined according to the method were compared with laboratory results of soil samples taken at the testing site. The agreement between the two parameter determination approaches was only not found for cohesion where there occurred an apparent discordance. This discordance in the values of cohesion points to the low reliability of the determination of cohesion in the laboratory. This is due to boundary conditions under which the test is performed and the quality of soil sample. Boundary conditions should be the same as on the actual construction site and the quality of the soil sample should be intact. Both are difficult to achieve at the same time in laboratory tests, because the conditions on the construction site are difficult to reproduce in their entirety in the laboratory and the quality of the sample is also affected by the handling of samples. All this is a major obstacle to finding a reliable value of cohesion. If the cohesion assessment is based on site tests, both the boundary condition and the quality of the sample are implicitly included in the test.

Execution of compression and traction tests on the same micropile at the construction site and evaluation of their diagrams displacement on load open up a simple and fast way to a quite reliable determination of shear strength parameters of soil ground and surmount a number of important factors that affect 
these parameters without being excluded from the evaluation or else having been determined to be of low reliability. This method brings a different approach to determination of the parameters in question or also their verification if they were determined by other methods.

\section{ACKNOWLEDGEMENTS}

The paper has been funded with the support of conceptual development of science, research and innovation in 2021, assigned to the VŠB-Technical University of Ostrava, The Ministry of Education, Youth and Sports in the Czech Republic. 